UNIVERSIDADE DE SÃO PAULO

ESCOLA DE EDUCAÇÃO FÍSICA E ESPORTE

INFLUÊNCIA DO GENE DA ENZIMA CONVERSORA DE ANGIOTENSINA

SOBRE AS RESPOSTAS METABÓLICAS INDUZIDAS PELO TREINAMENTO FÍSICO AERÓBIO EM CAMUNDONGOS DIABÉTICOS.

FABIO CARVALHO BERGAMO

SÃO PAULO

2010 
INFLUÊNCIA DO GENE DA ENZIMA CONVERSORA DE ANGIOTENSINA SOBRE AS RESPOSTAS METABÓLICAS INDUZIDAS PELO TREINAMENTO FÍSICO AERÓBIO EM CAMUNDONGOS DIABÉTICOS.

\section{FÁBIO CARVALHO BERGAMO}

Dissertação apresentada à Escola de Educação Física e Esporte da Universidade de São Paulo, como requisito parcial para obtenção do grau de Mestre em Educação Física.

ORIENTADORA: Prof ${ }^{a}$. Dr ${ }^{\mathrm{a}}$. FABIANA DE SANT`ANNA EVANGELISTA 


\section{Bergamo, Fábio Carvalho}

Influência do gene da enzima conversora de angiotensina sobre as respostas metabólicas induzidas pelo treinamento físico aeróbio em camundongos diabéticos / Fábio Carvalho Bergamo. - São Paulo : [s.n.], 2010. xiii, 84p.

Dissertação (Mestrado) - Escola de Educação Física e Esporte da Universidade de São Paulo.

Orientadora: Prof ${ }^{\mathrm{a}}$. Dr ${ }^{\mathrm{a}}$. Fabiana de Sant'Anna Evangelista.

Título.

1. Diabetes Experimental 2.Sistema Renina Angiotensina 3.Treinamento Físico I. 
Dedico aos meus pais e à minha avó Helena, pelo apoio incondicional desde o primeiro momento para realização desse sonho. 


\section{AGRADECIMENTOS}

Agradeço a Deus pela saúde, proteção e energia para enfrentar os momentos dessa longa caminhada, a vida.

À Profa. Dra. Fabiana de Sant'Anna Evangelista pela oportunidade, ensinamentos, paciência e, acima de tudo, pelo exemplo de luta e determinação. Sem os quais a realização deste não seria possível.

À Profa. Dra. Miriam Helena Fonseca Alaniz pelos ensinamentos e disponibilidade constante durante todo o processo, principalmente nas avaliações envolvendo o tecido adiposo.

Ao Prof. Dr. José Eduardo Krieger por colocar seu laboratório à disposição em tempo integral, possibilitando a realização do presente trabalho.

À Talita Sayuri Higa pela grande colaboração em todos os processos desse trabalho.

À Aline Villa Nova Bacurau pela colaboração nas avaliações envolvendo o músculo esquelético.

Aos amigos de laboratório, Jaqueline, Acauã e Flávio pela colaboração na realização desse trabalho.

Aos técnicos do laboratório Leandro, Newton e Mônica pela disponibilização e cuidado com os animais.

A todos os amigos da EEFE-USP, da divisão de experimentação e Laboratório de Genética e Cardiologia Molecular do InCor-SP que certamente contribuíram direta ou indiretamente para realização desse trabalho. 
À Ilza, Márcio e Luiz da secretaria de Pós-Graduação da Escola de Educação Física e Esporte da USP, sempre atentos e solícitos no atendimento ao aluno.

À Coordenação de Aperfeiçoamento de Pessoal de Nível Superior (CAPES) pela concessão da bolsa de mestrado. 
SUMÁRIO

Página

LISTA DE TABELAS vi

LISTA DE FIGURAS vii

LISTA DE SIGLAS, ABREVIAÇÕES E SÍMBOLOS ix

RESUMO $\mathrm{x}$

ABSTRACT xii

1 INTRODUÇÃO 1

2 OBJETIVO 6

2.1 Objetivo Geral 6

2.2 Objetivos Específicos 6

3 REVISÃO DA LITERATURA 7

$\begin{array}{lll}3.1 & \text { Diabetes } & 7\end{array}$

3.2 Sistema Renina Angiotensina 11

3.3 Diabetes e Sistema Renina Angiotensina 14

3.4 Adaptações metabólicas ao treinamento físico 16

$\begin{array}{lll}3.5 & \text { O modelo experimental } & 19\end{array}$

4 MATERIAIS E MÉTODOS 21

$\begin{array}{lll}4.1 & \text { Amostra } & 21\end{array}$

4.2 Modelo de camundongos geneticamente modificados 22

4.3 Planejamento dos cruzamentos dos camundongos com 1 a 4 cópias do 22 gene da ECA

4.4 Identificação dos animais 23

4.5 Genotipagem 23

4.6 Indução do Diabetes Experimental 24

4.7 Treinamento Físico 25

4.8 Avaliação da capacidade de esforço físico 25

4.9 Avaliações durante o protocolo experimental in vivo 26

4.9.1 Fatores determinantes do balanço energético 26

4.9.2 Teste de tolerância à glicose intraperitoneal (TTGI) 27 
4.10 Sacrifício e coleta de tecidos e sangue 27

4.11 Estudo do tecido adiposo branco 28

4.11.1 Extração dos adipócitos e análise morfométrica 28

4.11.2 Avaliação da atividade lipolítica frente ao estímulo com isoproterenol 29

4.11.3 Dosagem da atividade da enzima ácido graxo sintase (FAS) 30

4.12 Estudo do músculo esquelético 31

4.12.1 Dosagem da atividade máxima da enzima citrato sintase 31

4.12.2 Reação histoquímica para Miosina ATPase e determinação da tipagem 33 de fibras musculares

4.12.3 Quantificação de capilares no músculo esquelético 35

4.13 Desenho dos procedimentos experimentais 36

4.14 Análise Estatística 37

$5 \quad$ RESULTADOS 38

5.1 Composição Corporal 38

5.2 Consumo diário de ração 43

5.3 Metabolismo energético de repouso 44

5.4 Capacidade de realização de exercício físico 45

5.5 Avaliações Bioquímicas 46

5.5.1 Glicemia de Jejum 46

5.5.2 Teste de tolerância à glicose intraperitoneal 47

$\begin{array}{lll}5.5 .3 & \text { Insulina } & 49\end{array}$

$\begin{array}{llr}\text { 5.5.4 Leptina } & 50\end{array}$

5.6 Atividade Lipolítica 50

5.7 Atividade Lipogênica 51

5.8 Avaliações músculo-esqueléticas 53

6 DISCUSSÃO 56

6.1 Influência do genótipo da ECA no desenvolvimento do diabetes 56 experimental

6.2 Efeitos metabólicos do treinamento físico no diabetes experimental 61

7 CONCLUSÃO 71

$8 \quad$ REFERÊNCIAS 


\section{LISTA DE TABELAS}

Página

TABELA 1 - Separação dos grupos de animais submetidos ao protocolo 21 experimental

TABELA 2 - Ganho de peso corporal (PC) dos animais ao longo das 15 semanas de protocolo e Índice de Lee 


\section{LISTA DE FIGURAS}

Página

FIGURA1 - Loja muscular posterior após mergulhada no isopentano (A) e

Congelamento das amostras em nitrogênio líquido (B)

FIGURA 2 - Classificação dos tipos de fibras no músculo sóleo no pH 10,3............ 35

FIGURA 3 - Identificação dos capilares no músculo sóleo ....................................... 36

FIGURA 4 - Evolução do peso corporal dos animais durante o protocolo 38 experimental

FIGURA 5 - Ganho de peso corporal entre semana 1 e semana 7 (A) e entre a 39 semana 8 e semana 15 (B)

FIGURA 6 - Peso dos depósitos de gordura branca retroperitoneal e periepididimal (A) .Valores médios do diâmetro de adipócitos dos animais submetidos ao protocolo experimental (B)

FIGURA 7 - Imagens ilustrativas da quantificação do diâmetro dos adipócitos extraídos do tecido adiposo periepididimal

FIGURA 8 - Peso dos órgãos (A) e pesos dos músculos sóleo e gastrocnêmio (B) dos animais do protocolo experimental

FIGURA 9 - Consumo diário de ração por animal avaliado durante a sem 1 à sem 7 (A) e a sem 8 à sem 15 (B)

FIGURA 10 - Consumo de oxigênio $\left(\mathrm{VO}_{2}\right)$ de repouso dos animais submetidos ao protocolo experimental pré e pós treinamento físico

FIGURA 11 - Distância (A) e Tempo (B) avaliados no teste de esforço progressivo em esteira até exaustão realizado pré e pós-treinamento físico

FIGURA 12 - Glicemia de jejum obtida após o sacrifício

FIGURA 13 - Glicemia avaliada no teste de tolerância à glicose e área sob a curva (AUC) pré-treino (A) e pós-treino (B)

FIGURA 14 - Concentração de insulina sérica após o período de treinamento físico ..

FIGURA 15 - Concentração de leptina sérica após o período de treinamento físico .... 50

FIGURA 16 - Atividade lipolítica (A) e diferença entre as taxas de glicerol na 51 presença (Iso) e na ausência (Basal) de isoproterenol (B) em adipócitos de animais submetidos ao protocolo experimental 
FIGURA 17 - Atividade da enzima lipogênica ácido graxo sintase (FAS) no tecido 52 adiposo retroperitoneal

FIGURA 18 - Atividade da enzima lipogênica ácido graxo sintase (FAS) no tecido 52 hepático

FIGURA 19 - Atividade máxima da enzima citrato sintase no músculo sóleo 53

FIGURA 20 - Percentual de fibras musculares tipo I (A), Intermediárias (B) e tipo 54 IIA (C) no músculo sóleo

FIGURA 21 - Densidade de fibras no músculo sóleo inteiro 55

FIGURA 22 - Razão número de capilares por número de fibras no músculo sóleo 55 inteiro 
1S 1 Cópia da Enzima Conversora de Angiotensina Sedentário

$1 \mathrm{~T} \quad 1$ Cópia da Enzima Conversora de Angiotensina Treinado

3S 3 Cópias da Enzima Conversora de Angiotensina Sedentário

3T 3 Cópias da Enzima Conversora de Angiotensina Treinado

Acetil CoA Acetil Coenzima A

Ang I Angiotensina I

Ang II Angiotensina II

ATP Trifosfato de Adenosina

AUC Área Sob a Curva

CS Citrato Sintase

DM 1 Diabetes Mellitus Tipo 1

DNA Ácido Desoxirribonucleico

ECA Enzima Conversora de Angiotensina

eNOS Enzima Óxido Nítrico Sintase

EP Tecido Adiposo Periepididimal

FAS Ácido Graxo Sintase

G6PDH Glicose-6-Fosfato Desidrogenase

Gastro Gastrocnêmio

iECA Inibidor da Enzima Conversora de Angiotensina

I/D Inserção/Deleção

NAD Nicotinamida Adenina Dinucleotídeo

NADH Nicotinamida Adenina Dinucleotídeo Reduzida

$\mathrm{NADP}^{+} \quad$ Nicotinamida Adenina Dinucleotídeo Fosfato

NADPH Nicotinamida Adenina Dinucleotídeo Fosfato Reduzida

PCR Reação em cadeia da polimerase

RP Tecido adiposo retroperitoneal

SBD Sociedade Brasileira de Diabetes

SRA Sistema Renina Angiotensina

STZ Estreptozotocina

$\mathrm{VO}_{2} \quad$ Consumo de Oxigênio 
RESUMO

\title{
INFLUÊNCIA DO GENE DA ENZIMA CONVERSORA DE ANGIOTENSINA SOBRE AS RESPOSTAS METABÓLICAS INDUZIDAS PELO TREINAMENTO FÍSICO AERÓBIO EM CAMUNDONGOS DIABÉTICOS
}

\author{
Autor: FABIO CARVALHO BERGAMO \\ Orientador: PROF ${ }^{a}$. DR ${ }^{\mathrm{a}}$. FABIANA DE SANT’ ANNA EVANGELISTA
}

O objetivo do presente estudo foi avaliar os efeitos do treinamento físico (TF) sobre as alterações do metabolismo energético induzidas pelo diabetes em camundongos com 1 e 3 cópias do gene da enzima conversora de angiotensina (ECA). Para isso, camundongos machos C57BL/6 geneticamente modificados com 1 e 3 cópias do gene da ECA foram induzidos ao diabetes por estreptozotocina (STZ), e separados em 4 grupos de acordo com a realização ou não de TF com natação: 1 cópia sedentário (1S, n=14), 1 cópia treinado $(1 \mathrm{~T}, \mathrm{n}=15), 3$ cópias sedentário (3S, n=10), e 3 cópias treinado (3T, $\mathrm{n}=11$ ). Os principais resultados foram: não houve diferença no ganho de peso corporal, porém o peso do depósito de gordura retroperitoneal e diâmetro de adipócito foram menores no grupo $3 \mathrm{~T}$ comparado ao $1 \mathrm{~S}, 1 \mathrm{~T}$ e $3 \mathrm{~S}$; menor consumo de ração diária do $1 \mathrm{~S}$ comparado ao 1T, 3S e 3T; maior consumo de oxigênio de repouso do 3S comparado ao 1T e 3T; melhor capacidade de realizar exercício físico e menor glicemia de jejum do $1 \mathrm{~T}$ comparado ao $1 \mathrm{~S}$ e $3 \mathrm{~S}(1 \mathrm{~T}=305 \pm 34$ vs. $1 \mathrm{~S}=479 \pm 47$ e $3 \mathrm{~S}=496 \pm 49 \mathrm{mg} / \mathrm{dl})$; maior concentração de leptina no $1 \mathrm{~T}$ comparado ao $1 \mathrm{~S}(1 \mathrm{~T}=5,65 \pm 0,33$ vs $1 \mathrm{~S}=4,07 \pm 0,43 \mathrm{ng} / \mathrm{ml})$ 
e maior atividade lipolítica no $1 \mathrm{~T}$ comparada aos grupos $1 \mathrm{~S}, 3 \mathrm{~S}$ e $3 \mathrm{~T}(1 \mathrm{~T}=288 \pm 50$ $\mathrm{nmol} / 10^{6} \mathrm{cels} / \mathrm{h}$ vs. $1 \mathrm{~S}=79 \pm 37,3 \mathrm{~S}=123 \pm 37$ e $3 \mathrm{~T}=50 \pm 20 \mathrm{nmol} / 10^{6}$ cels $/ \mathrm{h}$ ); Não houve diferença estatística entre os grupos na tolerância à glicose, na atividade da enzima lipogênica ácido graxo sintase, na atividade da enzima citrato sintase, na tipagem de fibras e na razão capilar/fibra muscular do músculo sóleo. Esses resultados demonstraram que as adaptações metabólicas promovidas pelo TF no diabetes são parcialmente associadas ao genótipo da ECA.

Palavras-chave: diabetes experimental, sistema renina angiotensina, metabolismo energético, treinamento físico. 


\begin{abstract}
INFLUENCE OF ANGIOTENSIN CONVERTING ENZIME GENE ON METABOLIC RESPONSES INDUCED BY AEROBIC PHYSICAL TRAINING IN DIABETIC MICE
\end{abstract}

\author{
Author: FABIO CARVALHO BERGAMO \\ Advisor: PROF ${ }^{a}$. DR ${ }^{a}$. FABIANA DE SANT'ANNA EVANGELISTA
}

The main purpose of this study was to evaluate the effects of physical training (PT) on changes in energy metabolism induced by diabetes in mice harboring 1 and 3 copies of angiotensin converting enzyme (ACE) gene. For this, transgenic adult male mice (C57BL/6) with 1 or 3 copies of ACE gene were induced to diabetes by Streptozotocin (STZ) and separated into groups sedentary or physical trained with swimming: 1 copy sedentary $(1 \mathrm{~S}, \mathrm{n}=14), 1$ copy trained $(1 \mathrm{~T}, \mathrm{n}=15), 3$ copies sedentary $(3 S, n=10)$ and 3 copies trained $(3 T, n=11)$. The main results were: body weight gain was not different among groups, but $3 \mathrm{~T}$ group reduced retroperitoneal fat pad and adipocyte diameter compared to $1 \mathrm{~S}, 1 \mathrm{~T}$ and $3 \mathrm{~S}$ groups; daily food intake was lower in $1 \mathrm{~S}$ compared to $1 \mathrm{~T}, 3 \mathrm{~S}$ and $3 \mathrm{~T}$ groups; resting oxygen uptake was higher in $3 \mathrm{~S}$ compared to $1 \mathrm{~T}$ and 3T; physical exercise ability increased and fasting glucose decreased only in $1 \mathrm{~T}$ group compared to $1 \mathrm{~S}$ and $3 \mathrm{~S}(1 \mathrm{~T}=305 \pm 34$ vs. $1 \mathrm{~S}=479 \pm 47 \mathrm{e}$ $3 \mathrm{~S}=496 \pm 49 \mathrm{mg} / \mathrm{dl})$; serum leptin increased in $1 \mathrm{~T}$ compared to $1 \mathrm{~S}(1 \mathrm{~T}=5,65 \pm 0,33 \mathrm{vs}$ $1 \mathrm{~S}=4,07 \pm 0,43 \mathrm{ng} / \mathrm{ml}$ ), and lipolytic activity was higher in $1 \mathrm{~T}$ compared to $1 \mathrm{~S}, 3 \mathrm{~S}$ and $3 \mathrm{~T}$ 
groups $\left(1 \mathrm{~T}=288 \pm 50 \mathrm{nmol} / 10^{6} \mathrm{cels} / \mathrm{h} \quad\right.$ vs. $\quad 1 \mathrm{~S}=79 \pm 37, \quad 3 \mathrm{~S}=123 \pm 37$ e $3 \mathrm{~T}=50 \pm 20$ $\left.\mathrm{nmol} / 10^{6} \mathrm{cels} / \mathrm{h}\right)$. There were no statistical differences among groups in glucose tolerance, lipogenic activity of fat acid synthase, activity of citrate synthase enzyme, fibre type composition and capillary-to-fibre ratio of soleous muscle. These results demonstrated that metabolic adaptations promoted by PT in diabetes are partially associated with ACE genotype.

Keywords: experimental diabetes, renin-angiotensin system, energy metabolism, physical training. 